\title{
EVALUATION OF THE RESULTS FROM ARTHROSCOPIC REPAIR ON ROTATOR CUFF INJURIES AMONG PATIENTS UNDER 50 YEARS OF AGE
}

Alberto Naoki Miyazaki', Marcelo Fregoneze ${ }^{2}$, Pedro Doneux Santos ${ }^{3}$, Luciana Andrade da Silva ${ }^{3}$, Guilherme do Val Sella ${ }^{3}$, Ruy Mesquita Maranhão Santos ${ }^{4}$, Adriano de Souza ${ }^{4}$, Sérgio Luiz Checchia ${ }^{5}$

\begin{abstract}
Objective: To assess the results from arthroscopic surgical treatment of rotator cuff injuries among patients under 50 years of age. Methods: Sixty-three patients with rotator cuff injuries who underwent arthroscopic surgical treatment performed by the Shoulder and Elbow Group of the Department of Orthopedics and Traumatology, in the Fernandinho Simonsen wing of Santa Casa Medical School, São Paulo, between August 1998 and December 2007, were reassessed. The study included all patients with rotator cuff injuries who were under 50 years of age and had been followed up postoperatively for at least 24 months.
\end{abstract}

\section{INTRODUCTION}

Rotator cuff injuries are common in orthopedic practice, with prevalence ranging from 5 to $33 \%$ of the population ${ }^{(1-4)}$. Little information is available in the literature on this type of injury when it occurs in patients under the age of 50 years ${ }^{(5,6)}$. Hawkins et $\mathrm{al}^{(7)}$ demonstrated that out of 100 surgically treated patients within this age group, only two presented a complete rotator cuff tear.

While the population over the age of 50 years is
Results: According to the UCLA evaluation criteria, 59 patients $(92 \%)$ showed excellent and good results; five (8\%) showed fair results; and none showed poor results. The postoperative evaluation showed that the mean range of motion was $145^{\circ}$ for elevation, $47^{\circ}$ for lateral rotation and $\mathrm{T} 10$ for medial rotation. Unsatisfactory results were associated with prolonged duration of the injury, with a statistically significant relationship. Conclusion: Arthroscopic repair of rotator cuff injuries in young patients produces excellent or good results for most patients.

Keywords - Rotator Cuff; Arthroscopy; Evaluation Studies more commonly affected and tends to present larger injuries because of tendon degeneration, the young population (under the age of 50 years) has lesions that are predominantly of traumatic etiology $\mathrm{y}^{(1,5,6,8)}$.

With regard to healing, younger patients tend to evolve more satisfactorily, although there is still no evidence in the literature to sustain this affirmation ${ }^{(5)}$.

Very few scientific articles have documented the clinical results from arthroscopically treated rotator cuff injuries in young patients who make high func-

1. Assistant Professor and Head of the Shoulder and Elbow Surgery Group, Department of Orthopedics and Traumatology, School of Medical Sciences, Santa Casa de São Paulo, São Paulo, Brazil.

2. Assistant Professor and Attending Physician in the Shoulder and Elbow Surgery Group, Department of Orthopedics and Traumatology, School of Medical Sciences, Santa Casa de São Paulo, São Paulo, Brazil.

3. Attending Physician in the Shoulder and Elbow Surgery Group, Department of Orthopedics and Traumatology, School of Medical Sciences, Santa Casa de São Paulo, São Paulo, Brazil.

4. Trainee in the Shoulder and Elbow Surgery Group, Department of Orthopedics and Traumatology, School of Medical Sciences, Santa Casa de São Paulo, São Paulo, Brazil.

5. Adjunct Professor, Academic Consultant and Member of the Shoulder and Elbow Surgery Group, Department of Orthopedics and Traumatology, School of Medical Sciences, Santa Casa de São Paulo, São Paulo, Brazil.

Work performed in the Department of Orthopedics and Traumatology, School of Medical Sciences, Santa Casa de São Paulo (DOT-FCMSCSP), "Fernandinho Simonsen" Wing, São Paulo (SP), Brazil. Director: Prof. Dr. Osmar Avanzi.

Correspondence: Rua Dr. Cesário Mota Jr., 112 - Vila Buarque - 01221-020 - São Paulo, SP. Site: www.ombro.med.br - E-mail: ombro@ombro.med.br

Work received for publication: February 17, 2010; accepted for publication: April 21, 2010.

The authors declare that there was no conflict of interest in conducting this work 
tional demands (both professional and sporting) ${ }^{(9,10)}$. Some authors have demonstrated satisfactory longterm clinical results in patients aged up to 50 years who were operated to treat rotator cuff injuries ${ }^{(5,7,11-14)}$.

The aim of this study was to assess the clinical results obtained from arthroscopic treatment of rotator cuff injuries in patients aged up to 50 years.

\section{Sample and Methods}

Between August 1998 and December 2007, 89 patients with rotator cuff injuries underwent arthroscopic surgical treatment performed by the Shoulder and Elbow Group of the Department of Orthopedics and Traumatology, School of Medical Sciences, Santa Casa de Paulo, "Fernandinho Simonsen" Wing. Out of this total, 63 patients were reassessed, since 26 were lost because they did not fulfill the minimum criteria for the postoperative follow-up. The inclusion criteria taken for this study were that the subjects should be patients aged up to 50 years who were operated due to complete rotator cuff tears and were followed up postoperatively for at least two years. The exclusion criteria were that these patients should not present a partial tear; or a complete tear with age greater than 50 years; or a postoperative time of less than two years.

There were 36 male patients (57.1\%) and 27 females $(42.8 \%)$. The mean age was 44.8 years, with a range from 32 to 50 years. The duration of pain before the operation ranged from one to 192 months, with a mean of 21 months. The dominant side was affected in 55 cases $(87.3 \%)$, and two cases were bilateral (cases 3 and 7). Among the injuries, 23 (36.5\%) resulted from trauma or high physical demand on the shoulder affected. There were also 23 patients $(36.5 \%)$ who practiced sports in which they used their arms, and of these, nine $(39.1 \%)$ presented associated traumatic etiology (Table 1).

In relation to the initial size of the lesion, according to the classification of Hawkins et al ${ }^{(7)}, 22$ were small $(33.8 \%)$, 33 were medium $(50.7 \%)$ and ten were large $(15.5 \%)$. No cases of extensive lesions were observed (Figure 1).

All the patients underwent the surgical procedure in the "deckchair" position, under general anesthesia associated with anesthetic block of the brachial plexus. Arthroscopic inspection of the joint was perfor-

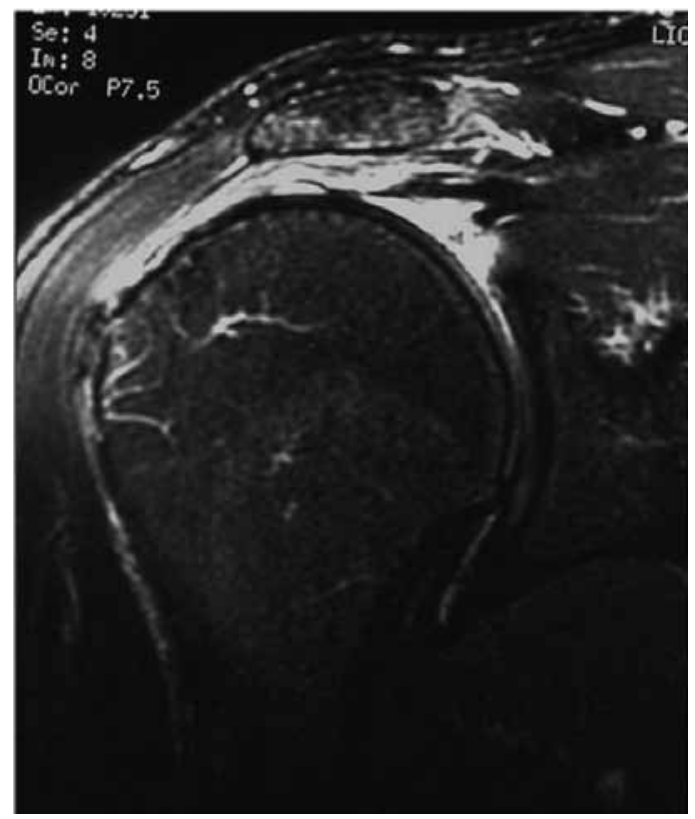

Figure 1 - T2 magnetic resonance image of right shoulder in coronal slice, showing large lesion in the supraspinatus tendon.

med before repairing the cuff. The subacromial space was then opened, and bursal debridement, tendon mobilization and bleeding of the bone bed of the humeral head were performed. Resection of the lateral portion of the clavicle, tenotomy and tenodesis of the long head of the biceps were performed as associated procedures, as necessary (Table 1). Acromioplasty was performed on all the patients. The suturing was done as a single row using between one and four anchors (mean of 1.5). None of the cases were sutured in a double row (Figures 2 and 3 ).

The mean duration of postoperative immobilization, using a functional sling, was seven weeks, with a range from four to twelve weeks.

During the postoperative period, the patients were reassessed clinically using the method of the University of California at Los Angeles (UCLA) ${ }^{(15)}$. Joint mobility was assessed using the parameters described by Hawkins and Bokos ${ }^{(8)}$.

For the statistical analysis, version 17.0 of the SPSS software (Statistical Package for the Social Sciences) was used to obtain the results, and an interval of $95 \%$ was considered statistically significant $(\mathrm{p}<0.005)$. The Mann-Whitney test was applied to the trauma variables and UCLA score; Spearman's correlation analysis, to the duration of symptoms and UCLA score; and the Kruskal-Wallis test to lesions size and UCLA score. 
Table 1 - Demographic data, procedures performed and results.

\begin{tabular}{|c|c|c|c|c|c|c|c|c|c|c|c|c|}
\hline Pat & Sex & Dom & Sp & $\operatorname{Tr}$ & $A L$ & MUM & TB & $\Delta \mathrm{T}$ & Siz & $\Delta \mathrm{tt}$ & UCLA & COMPLIC \\
\hline 1 & $\mathrm{~F}$ & + & & + & + & + & & 8 & $\mathrm{G}$ & 36 & 23 & \begin{tabular}{|l|} 
torn again \\
\end{tabular} \\
\hline 2 & $\mathrm{~F}$ & + & & & & & & 12 & $M$ & 24 & 33 & \\
\hline 3 & $\mathrm{~F}$ & + & & + & & & & 2 & $P$ & 124 & 35 & \\
\hline 3 & $\mathrm{~F}$ & & & & & & & 24 & $P$ & 93 & 33 & \\
\hline 4 & $\mathrm{~F}$ & + & & & + & + & & 24 & $M$ & 39 & 21 & torn again \\
\hline 5 & $\mathrm{~F}$ & & & + & + & + & & 12 & $\mathrm{M}$ & 86 & 35 & \\
\hline 6 & $\mathrm{~F}$ & + & & & & & & 11 & $M$ & 80 & 33 & \\
\hline 7 & $\mathrm{~F}$ & + & & & + & + & & 60 & $\mathrm{P}$ & 71 & 31 & \\
\hline 7 & $\mathrm{~F}$ & + & & & + & + & & 48 & $\mathrm{P}$ & 36 & 33 & \\
\hline 8 & $\mathrm{M}$ & + & & + & + & & & 26 & $\mathrm{G}$ & 25 & 35 & \\
\hline 9 & $F$ & & & + & + & & & 24 & $\mathrm{G}$ & 42 & 35 & \\
\hline 10 & $F$ & + & & & + & + & & 42 & $M$ & 31 & 29 & \\
\hline 11 & $\mathrm{M}$ & + & & + & & & & 24 & $\mathrm{G}$ & 28 & 23 & torn again \\
\hline 12 & $\mathrm{~F}$ & + & & + & & & & 24 & $\mathrm{P}$ & 28 & 22 & $\begin{array}{c}\text { joint } \\
\text { stiffness }\end{array}$ \\
\hline 13 & $F$ & & & & & & & 36 & $P$ & 24 & 29 & \\
\hline 14 & $\mathrm{M}$ & + & & & & & & 11 & $G$ & 24 & 27 & torn again \\
\hline 15 & $\mathrm{M}$ & + & + & & & & & 192 & $\mathrm{P}$ & 22 & 35 & \\
\hline 16 & $\mathrm{~F}$ & + & & & & & & 6 & $\mathrm{M}$ & 39 & 33 & \\
\hline 17 & $M$ & + & & & & & & 12 & $M$ & 52 & 35 & \\
\hline 18 & $\mathrm{M}$ & + & + & + & + & & & 2 & $\mathrm{P}$ & 24 & 35 & \\
\hline 19 & $\mathrm{M}$ & + & + & & & & & 2 & $M$ & 65 & 35 & \\
\hline 20 & $\mathrm{M}$ & + & & + & & & & 1 & $\mathrm{P}$ & 24 & 35 & \\
\hline 21 & $M$ & + & & & . & & & 6 & $M$ & 82 & 35 & \\
\hline 22 & $\mathrm{~F}$ & + & & & + & + & & 24 & $P$ & 90 & 35 & \\
\hline 23 & $\mathrm{M}$ & + & & + & & & & 1 & $M$ & 115 & 35 & \\
\hline 24 & $M$ & + & & + & & & & 1 & $P$ & 49 & 35 & \\
\hline 25 & $\mathrm{M}$ & + & & + & + & & & 1 & $P$ & 79 & 35 & \\
\hline 26 & $M$ & + & & + & & & & 2 & $M$ & 33 & 35 & \\
\hline 27 & $\mathrm{M}$ & + & & + & + & & & 1 & $M$ & 60 & 33 & \\
\hline 28 & $\mathrm{~F}$ & + & + & & + & + & & 6 & $M$ & 54 & 35 & \\
\hline 29 & $M$ & & + & + & + & & & 2 & $\mathrm{P}$ & 56 & 35 & \\
\hline 30 & $M$ & & + & + & & & & 1 & $\mathrm{G}$ & 48 & 35 & \\
\hline 31 & $\mathrm{~F}$ & + & + & & & & & 5 & $\mathrm{M}$ & 47 & 35 & \\
\hline 32 & $M$ & + & + & & & & & 2 & $M$ & 46 & 35 & \\
\hline 33 & $M$ & + & & & 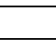 & & & 13 & $M$ & 44 & 35 & \\
\hline 34 & $M$ & + & + & & + & & & 12 & $\mathrm{P}$ & 46 & 32 & \\
\hline 35 & $M$ & & + & & + & & + & 1 & $M$ & 24 & 35 & \\
\hline 36 & $M$ & + & + & & + & & + & 84 & $M$ & 40 & 35 & \\
\hline 37 & $\mathrm{~F}$ & + & + & & & & & 12 & $M$ & 24 & 35 & \\
\hline 38 & $\mathrm{~F}$ & + & + & & + & + & & 12 & $M$ & 35 & 35 & \\
\hline 39 & $\mathrm{~F}$ & + & & & + & & & 6 & $\mathrm{P}$ & 26 & 35 & \\
\hline 40 & $\mathrm{M}$ & & & + & + & & & 1,5 & $M$ & 25 & 35 & \\
\hline 41 & $M$ & + & + & & + & & & 48 & $\mathrm{M}$ & 24 & 35 & \\
\hline 42 & $\mathrm{M}$ & + & + & & + & + & & 6 & $M$ & 60 & 35 & \\
\hline 43 & $\mathrm{~F}$ & + & + & & & & & 24 & $M$ & 81 & 35 & \\
\hline 44 & $\mathrm{~F}$ & + & & 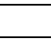 & & & & 3 & $\mathrm{M}$ & 32 & 35 & \\
\hline 45 & $M$ & + & + & + & & & & 1 & $\mathrm{G}$ & 122 & 35 & \\
\hline 46 & $M$ & + & + & + & & 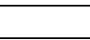 & & 5 & $M$ & 25 & 35 & \\
\hline 47 & $\mathrm{~F}$ & + & & & + & + & & 24 & $\mathrm{P}$ & 28 & 33 & \\
\hline 48 & $M$ & + & + & & & & & 4 & $\mathrm{P}$ & 103 & 35 & \\
\hline 49 & $\mathrm{~F}$ & + & + & & & & & 5 & $M$ & 101 & 35 & \\
\hline 50 & $M$ & + & + & + & & & & 1 & $\mathrm{G}$ & 104 & 35 & \\
\hline 51 & $\mathrm{~F}$ & & + & & + & + & & 6 & $\mathrm{P}$ & 93 & 33 & \\
\hline 52 & $\mathrm{~F}$ & + & + & & & & & 6 & $\mathrm{G}$ & 102 & 35 & \\
\hline 53 & $M$ & + & + & & + & + & & 6 & $\mathrm{G}$ & 106 & 35 & \\
\hline 54 & $M$ & + & + & + & & & & 24 & $M$ & 92 & 35 & \\
\hline 55 & $M$ & + & + & & + & & & 60 & $M$ & 84 & 29 & \\
\hline 56 & $\mathrm{M}$ & + & + & + & & & & 180 & $\mathrm{P}$ & 61 & 35 & \\
\hline 57 & $M$ & + & + & & + & + & & 2 & $M$ & 90 & 35 & \\
\hline 58 & $\mathrm{M}$ & + & + & + & + & & & 3 & $\mathrm{P}$ & 82 & 33 & \\
\hline 59 & $M$ & + & & & + & + & + & 36 & $P$ & 45 & 32 & \\
\hline 60 & $\mathrm{M}$ & + & + & & & & & 12 & $\mathrm{P}$ & 80 & 35 & \\
\hline 61 & $\mathrm{~F}$ & & & & & & & 24 & $M$ & 78 & 35 & \\
\hline 62 & $M$ & + & + & & + & & & 5 & $M$ & 76 & 35 & \\
\hline 63 & $M$ & + & + & & + & & & 96 & $M$ & 65 & 35 & \\
\hline
\end{tabular}

Source: Medical files of DOT-SCMSP

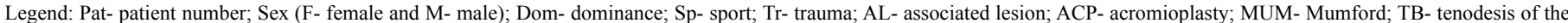

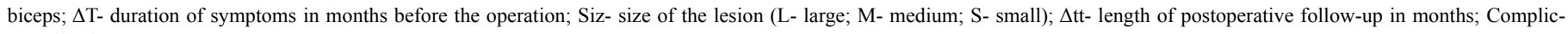
complication. 


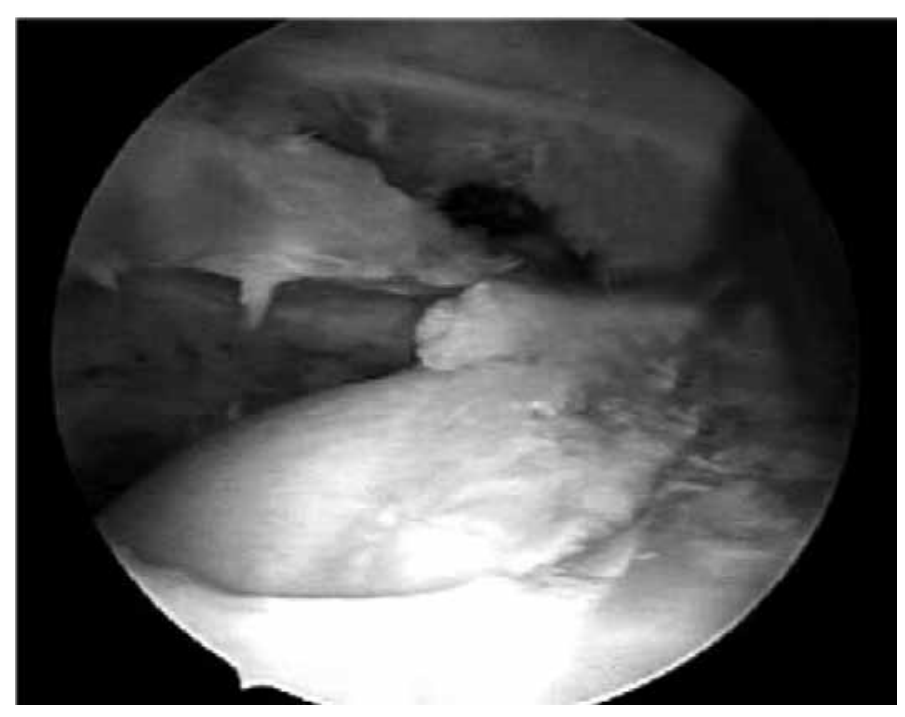

Figure 2 - Arthroscopic image (posterior portal) of rotator cuff injury to the right shoulder.

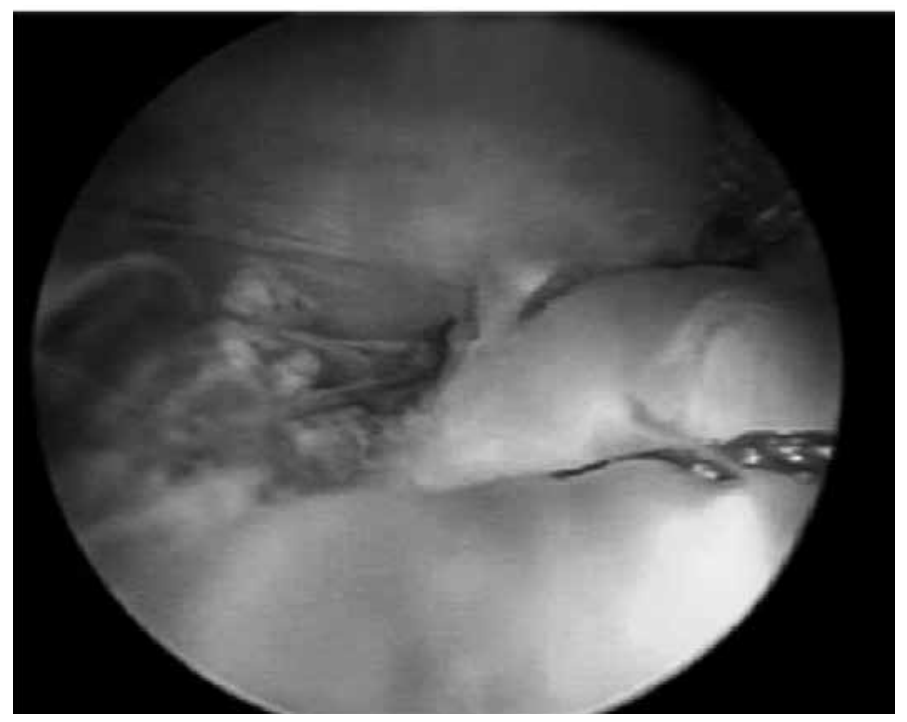

Figure 3 - Arthroscopic image (posterior portal) after suturing of the rotator cuff injury to the right shoulder.

\section{RESULTS}

From analysis on the results from the 63 patients who were operated, we found that the mean UCLA score was 33.3 points (range: 21 to 35 ). The results were considered excellent in $71.4 \%$ of the cases and good in $20.6 \%$ (Table 1 ). The results were unsatisfactory in $8 \%$ (five cases), which were classified as fair (Table 1).

The mean range of motion in the postoperative evaluation was $145^{\circ}$ for elevation, ranging from $80^{\circ}$ to $160^{\circ} ; 47^{\circ}$ for lateral rotation, ranging from $35^{\circ}$ to $60^{\circ}$; and T10 for medial rotation, ranging from L 3 to
T5. The mean length of follow-up after the operation was 58 months, ranging from 24 to 124 months.

The statistical analysis did not show any statistically significant correlation between lesion size and the presence of trauma, in comparison with the results $(p>0.050)$. On the other hand, the duration of the symptoms had a statistically significant relationship $(p=0.003)$ with the results, given that the greater the time elapsed between the injury and the surgery, the worse the results were.

From evaluating our unsatisfactory results, five cases $(8 \%)$ presented a fair UCLA score. Of these, four cases presented new symptomatic tears, proven using magnetic resonance (cases 1, 4, 11 and 14); and one case presented mobility limitations and significant symptoms (case 12).

\section{DISCUSSION}

Complete tearing of the rotator cuff in patients in their first five decades of life is rare, although it has already been described by some authors ${ }^{(5,11,16)}$. Anatomical studies on cadavers have shown that degeneration of the rotator cuff is a normal process of human aging ${ }^{(11,17-19)}$. However, the etiological factors involved in rotator cuff injuries in young patients differ from those in elderly individuals ${ }^{(18,21)}$. While impact syndrome and tendon degeneration predominate in elderly individuals, young individuals show associations with traumatic mechanisms, especially glenohumeral dislocation ${ }^{(11)}$.

Rotator cuff injuries resulting from a single episode of trauma are rare. Cofield et $\mathrm{al}^{(21)}$ found that the incidence of an acute traumatic event was $8 \%$ in a series of 510 patients who were treated surgically for rotator cuff injuries. However, in our study, 23 patients $(36.5 \%)$ reported that the start of symptoms in the shoulder was associated with traumatic etiology.

Imaging studies using magnetic resonance have shown rates of new tears following arthroscopic repair that range from 31 to $94 \%$, and most cases have been asymptomatic $^{(22-24)}$. In the present sample, we found new tears in four cases $(6.5 \%)$, which were symptomatic and proven through imaging examinations.

Among these four cases of symptomatic new tears, the primary lesion was large in three cases and medium-sized in one case. Only two of the cases were 
associated with an initial traumatic mechanism (cases 1 and 11). The fifth case of dissatisfaction (case 12) consisted of limitations to mobility that were observed during the postoperative follow-up. We believe that the prolonged duration of symptoms in this case may have caused the unfavorable result.

\section{CONCLUSION}

Arthroscopic treatment of rotator cuff injuries in patients aged up to 50 years gave rise to a rate of excellent and good results of $92 \%$, when assessed using the UCLA functional method.

\section{REFERENCES}

1. Hattrup SJ. Rotator cuff repair: relevance of patient age. J Shoulder Elbow Surg. 1995;4(2):95-100.

2. Bigliani LU, Morrison DS, April EW. The morphology of the acromion and its relationship to rotator cuff tears. Orthop Trans. 1986;10:228.

3. Neer CS 2nd. Impingement lesions. Clin Orthop Relat Res. 1983;(173):70-7.

4. McLaughlin HL. Rupture of the rotator cuff. J Bone Joint Surg Am. 1962;44(5):979-83.

5. Burns JP, Snyder SJ. Arthroscopic rotator cuff repair in patients younger than fifty years of age. J Shoulder Elbow Surg. 2008;17(1):90-6.

6. Sperling JW, Cofield RH, Schleck C. Rotator cuff repair in patients fifty years of age and younger. J Bone Joint Surg Am. 2004;86(10):2212-5

7. Hawkins RJ, Misamore GW, Hobeika PE. Surgery for full-thickness rotator-cuff tears. J Bone Joint Surg Am. 1985;67(9):1349-55.

8. Hawkins RJ, Bokos DJ. Clinical evaluation of shoulder problems. In: Rockwood CA Jr, Matsen FA 3rd. The shoulder. 2nd ed. Philadelphia: Saunders; 1998. p.175-80.

9. Boileau P, Brassart N, Watkinson DJ, Carles M, Hatzidakis AM, Krishnan SG. Arthroscopic repair of full-thickness tears of the supraspinatus: does the tendon really heal? J Bone Joint Surg Am. 2005;87(6):1229-40

10. Harryman DT 2nd, Mack LA, Wang KY, Jackins SE, Richardson ML, Matsen FA 3rd. Repairs of the rotator cuff. Correlation of functional results with integrity of the cuff. J Bone Joint Surg Am. 1991;73(7):982-9.

11. Hawkins RJ, Morin WD, Bonutti PM. Surgical treatment of full-thickness rotator cuff tears in patients 40 years of age or younger. J Shoulder Elbow Surg. 1999;8(3):259-65.

12. Debeyre J, Patie D, Elmelik E. Repair of ruptures of the rotator cuff of the shoulder. J Bone Joint Surg Br. 1965;47:36-42

13. Godsil RD Jr, Linscheid RL. Intratendinous defects of the rotator cuff. Clin Orthop Relat Res. 1970;69:181-8.
14. McLaughlin HL. Repair of major cuff ruptures. Surg Clin North Am. 1963;43:1535-40.

15. Ellman H, Hanker G, Bayer M. Repair of the rotator cuff. End-result study of factors influencing reconstruction. J Bone Joint Surg Am. 1986;68(8):1136-44.

16. Krishnan SG, Harkins DC, Schiffern SC, Pennington SD, Burkhead WZ. Arthroscopic repair of full-thickness tears of the rotator cuff in patients younger than 40 years. Arthroscopy. 2008;24(3):324-8.

17. Veado MA, Almeida Filho IA, Duarte RG, Leitão I. Avaliação funcional do reparo artroscópico das lesões completas do manguito rotador associado a acromioplastia. Rev Bras Ortop. 2008;43(11-12):505-12.

18. Godinho GG. Reparação artroscópica do manguito rotator do ombro:avaliação funcional dos resultados de 87 pacientes [tese]. São Paulo; Universidade Federal de São Paulo, Escola Paulista de Medicina; 2002.

19. Miyazaki NA. Avaliação da reparação sob visão artroscópica das lesões do manguito rotador [tese]. São Paulo; Faculdade de Ciências Médicas da Santa Casa de São Paulo; 2005.

20. Apreleva M, Ozbaydar M, Fitzgibbons PG, Warner JJ. Rotator cuff tears: the effect of the reconstruction method on three-dimensional repair site area. Arthroscopy. 2002;18(5):519-26.

21. Cofield RH. Rotator cuff disease of the shoulder. J Bone Joint Surg Am. 1985;67(6):974-9.

22. Neviaser RJ. Evaluation and management of failed rotator cuff repairs. Orthop Clin North Am. 1997;28(2):215-24

23. Cummins CA, Murrell GA. Mode of failure for rotator cuff repair with suture anchors identified at revision surgery. J Shoulder Elbow Surg. 2003;12(2):128-33.

24. Hanusch BC, Goodchild L, Finn P, Rangan A. Large and massive tears of the rotator cuff: functional outcome and integrity of the repair after a mini-open procedure. J Bone Joint Surg Br. 2009;91(2):201-5. 